\title{
MAIS ALÉM DOS TRANSTORNOS DO NEURODESENVOLVIMENTO: desdobramentos para a infância e a educação
}

\author{
Thais Klein \\ Centro Universitário Augusto Motta (UNISUAM) \\ Rio de janeiro, RJ, Brasil \\ Rossano Cabral Lima \\ Universidade do Estado do Rio de Janeiro (UERJ) \\ Rio de Janeiro, RJ, Brasil
}

DOI: https://doi.org/10.22409/mov.v7i15.42885

\begin{abstract}
RESUMO
A publicação do DMS-5 em 2013, embora marcada por uma série de críticas, introduziu um novo capítulo, intitulado de "Transtornos do Neurodesenvolvimento", que foi recebido como uma espécie de promessa da psiquiatria contemporânea. A lógica mais ampla articulada a este grupo diagnóstico, ao abarcar uma série de quadros iniciados na infância sob a égide de uma etiopatogênese ligada ao desenvolvimento neuronal, aponta para novos direcionamentos no campo da psiquiatria, tal como o projeto Rdoc. O objetivo deste artigo é apresentar, por meio de bibliografia selecionada, a perspectiva neurodesenvolvimentista articulada à ascensão dos "Transtornos do Neurodesenvolvimento", procurando traçar correlações com os fenômenos da neurocultura, neuroidentidades e neurodiversidade, bem como identificar as noções de normalidade e patologia implícitas nesta lógica. Ademais, aponta-se algumas consequências desse paradigma no âmbito da infância e da educação. Pode-se perceber que os ideais sociais ligados às noções de competência e agência têm reconfigurado a percepção da infância contemporânea, associando-a a valores como autonomia e adaptabilidade, tornando a distinção entre crianças e adultos menos marcada. Estes valores estão em sintonia com a noção de neurodesenvolvimento, na medida em que ambos implicam uma trajetória de constante mudança, reconfiguração e aprendizagem ao longo da vida. O campo da educação é afetado por essa discussão, sendo invadido por metáforas cerebrais em torno da neuroplasticidade que, associadas à ênfase no empreendedorismo e do manejo de riscos, levam a deslocamentos na identidade da criança e do adolescente contemporâneos.
\end{abstract}

Palavras-chave: Neurodesenvolvimento. Psiquiatria. Infância. Educação. 


\title{
BEYOND THE NEURODEVELOPMENTAL DISORDERS:
} repercussions for childhood and education

\begin{abstract}
The publication of DMS-5 in 2013, although marked by a series of critics, had introduced a new chapter, entitled "Disorders of Neurodevelopment", which was received as a kind of promise in contemporary psychiatry. The broader logic articulated to this diagnostic group, when encompassing a series of conditions initiated in childhood under the aegis of an etiopathogenesis linked to neuronal development, points to new directions in the field of psychiatry, such as the Rdoc project. The objective of this paper is to present, through selected bibliography, the neurodevelopmental perspective articulated to the rise of the chapter "Neurodevelopmental Disorders", seeking to trace correlations with the phenomena of neuroculture, neuroidentities and neurodiversity, as well as to identify the notions of normality and pathology implicit in this logic. In addition, some consequences of this paradigm are pointed out in the context of childhood and education. The social ideals linked to the notions of competence and agency have reconfigured the perception of contemporary childhood, associating it with values such as autonomy and adaptability, making the distinction between children and adults less marked. These values are syntonised with the notion of neurodevelopment, as both imply a trajectory of constant change, reconfiguration and lifelong learning. The field of education is affected by this discussion, being invaded by brain metaphors around neuroplasticity that, associated with the emphasis on entrepreneurship and risk management, lead to shifts in the identity of contemporary children and adolescents. Key-words: Neurodevelopment. Psychiatry. Childhood. Education.
\end{abstract}

\section{MÁS ALLÁ DE LOS TRASTORNOS DEL NEURODESAROLLO: repercusiones para la infancia y la educación}

\begin{abstract}
RESUMEN
La publicación de DMS-5 en 2013, aunque marcada por una serie de críticas, introdujo un nuevo capítulo, titulado "Trastornos del neurodesarrollo", que fue recibido como una especie de promesa de la psiquiatría contemporánea. La lógica más amplia articulada a este grupo de diagnóstico abarca una serie de afecciones iniciadas en la infancia bajo los auspicios de una etiopatogenia vinculada al desarrollo neuronal y apunta a nuevas direcciones en el campo de la psiquiatría, como el proyecto Rdoc. El objetivo de este artículo es presentar, a través de bibliografía seleccionada, la perspectiva del neurodesarrollo articulada al surgimiento de los "trastornos del neurodesarrollo", buscando rastrear correlaciones con los fenómenos de la neurocultura, neuroidentidades y neurodiversidad, así como identificar las nociones de normalidad y patología
\end{abstract}




\section{movim nto \\ revista de educação do \\ programa de pós-graduação \\ faculdade de educação \\ ano 7 - número 15 - 2020}

implícitas en esta lógica. Además, se señalan algunas consecuencias de este paradigma en el contexto de la infancia y la educación. Se puede ver que los ideales sociales vinculados a las nociones de competencia y agencia han reconfigurado la percepción de la infancia contemporánea, asociándola con valores como la autonomía y la adaptabilidad, haciendo que la distinción entre niños y adultos sea menos marcada. Estos valores están en línea con la noción de neurodesarrollo, ya que ambos implican una trayectoria de cambio constante, reconfiguración y aprendizaje permanente. El campo de la educación se ve afectado por esta discusión, siendo invadida por metáforas cerebrales en torno a la neuroplasticidad que, asociadas con el énfasis en el espíritu empresarial y la gestión de riesgos, conducen a cambios en la identidad de los niños y adolescentes contemporáneos.

Palabras clave: Neurodesarollo. Psiquiatría. Infancia. Educación.

\section{Introdução}

A publicação da quinta edição do Manual Estatístico e Diagnóstico dos Transtornos Mentais (DSM-5), em 2013, foi recebida com uma série de críticas. Conforme aponta Costa (2014), longe de ter constituído um triunfo das convenções diagnósticas sistematizadas em psiquiatria, o DSM-5 terminou por expor uma fratura epistemológica fundamental nessa disciplina. Pouco antes do lançamento deste manual, foi publicado por Thomas Insel, diretor do National Institute of Mental Health (NIMH) dos EUA, um post intitulado Transforming Diagnosis no blog oficial do instituto.

Segundo Insel (2013), as categorias diagnósticas do DSM, baseadas em conjuntos de sintomas clínicos e não em medidas laboratoriais objetivas (como em outras áreas da medicina), não teriam validade científica - o projeto intitulado RDoc (Research Domain Criteria) foi apresentado como alternativa no sentido de fomentar a investigação dos transtornos mentais articulados ao aparato biológico. De acordo com Zorzanelli, Dalgalarrondo e Banzato (2014), o sentido de validade adotado por Insel (2013) diz respeito a uma inscrição biológica definida, dada sua suposição de que doenças mentais são desordens que envolvem circuitos cerebrais relacionados a domínios específicos como a cognição, emoção e comportamento.

O cenário, todavia, se mostra diferente em relação a um capítulo apresentado pela primeira vez na quinta edição do manual: os "Transtornos do 


\section{movim nto \\ revista de educação do \\ programa de pós-graduação \\ faculdade de educação \\ ano 7 - número 15 - 2020}

Neurodesenvolvimento". O advento deste grupo em 2013 marca o desaparecimento da seção "Transtornos usualmente evidentes pela primeira vez na infância e adolescência", presente nas edições anteriores desde o DSM-III (APA,1980). Alocados no início do Manual, cuja organização refletiria "uma abordagem cronológica do ciclo vital" (APA, 2013, p.13), os transtornos do neurodesenvolvimento agrupam as Deficiências intelectuais, os Transtornos da comunicação, os Transtorno específico da aprendizagem, os Transtornos motores e também o Transtorno do déficit de atenção e hiperatividade (TDAH) e os Transtornos do espectro autista. Nessa mesma direção, a CID 11, publicada em 2018, renomeou o que na CID 10 era o capítulo Transtornos mentais e do Comportamento para Transtornos mentais, do Comportamento e do Neurodesenvolvimento (Cap. 6 - 6 A00 - 6 E6Z).

O capítulo Transtornos do Neurodesenvolvimento não foi recebido com o descontentamento semelhante ao direcionado ao restante do DSM-5, mas, ao contrário, comporta uma lógica mais ampla que se configura como uma espécie de promessa da psiquiatria contemporânea ao abarcar diagnósticos destinados à infância sob a égide de uma etiopatogênese ligada ao desenvolvimento neuronal. Cassey, Olivieri e Insel (2014), por exemplo, indicam que a perspectiva neurodesenvolvimentista vai ao encontro das diretrizes recentes do Instituto Nacional de Psiquiatria (NIMH), mais especificamente ao projeto Rdoc, que visa fornecer uma nova diretriz nas pesquisas, distanciando-se de descrições sintomatológicas e prometendo mais validade e confiabilidade do que as classificações existentes. Este capítulo condensa, portanto, o projeto da psiquiatria contemporânea apoiado em convertê-la - pelo menos em parte - em "psiquiatria do desenvolvimento" (EME, 2017).

A perspectiva neurodesenvolvimentista se sustenta em uma noção de desenvolvimento de longo prazo, que se inicia na tenra infância (por vezes na vida intrauterina) e se estende na idade adulta - lógica que implica o deslocamento da noção moderna de desenvolvimento entendida como trajetória pré-estabelecida e calcada sobretudo na ideia de evolução. Ao se associar a noções da biologia como 


\section{movim nto \\ revista de educaçāo do \\ programa de pós-graduação \\ faculdade de educação \\ ano 7 - número 15 - 2020}

de epigenética e plasticidade cerebral, o neurodesenvolvimento remete a um processo errático e de constante transformação. Conforme aponta Nestler (2009), a articulação das patologias mentais aos transtornos do neurodesenvolvimento compõe um cenário no qual a patologia ganha caráter crônico, lento e progressivo. Ademais, sob este viés, nota-se a defesa da necessidade de compreender as patologias mentais a partir de uma diferença quantitativa do desenvolvimento normal (no sentido de excessos ou déficits), destacando a dimensão longitudinal.

A lógica neurodesenvolvimentista ultrapassa o capítulo dos transtornos do neurodesenvolvimento e atualiza a discussão em torno da figura do "sujeito cerebral" (EHRENBERG, 2009; VIDAL, 2005; VIDAL, ORTEGA, 2017) e, em um aspecto mais amplo, da "neurocultura" (ORTEGA, 2009). Isto porque, ao circunscrever os critérios de normalidade e patologia articulados ao desenvolvimento neural, esta perspectiva ajuda a produzir no imaginário social a percepção do cérebro como detentor das propriedades, autor das ações e matériaprima principal da identidade pessoal, entendida como identidade cerebral. Conforme aponta Ortega (2009), o sujeito cerebral está articulado à formação de neuroidentidades, isto é, formas de circunscrever as identidades baseadas na neurobiologia.

Diante dessas considerações, o objetivo deste artigo é apresentar mais detalhadamente a perspectiva neurodesenvolvimentista articulada à ascensão do capítulo Transtornos do Neurodesenvolvimento no DSM-5 e identificar as noções de normalidade e patologia articuladas a esta lógica. Ademais, procura-se circunscrever algumas correlações com o fenômeno da produção de neuroidentidades (como o movimento da neurodiversidade), apontando consequências desse paradigma no âmbito da infância e da educação.

\section{Neurodesenvolvimento e a psiquiatria contemporânea}

A articulação entre psiquiatria e desenvolvimento não é recente - Foucault (2001), por exemplo, afirma que a psiquiatria nasce vinculada a um ideário de desenvolvimento moderno. Grosso modo, essa noção se ancora em fases mais ou 


\section{movim nto \\ revista de educação do \\ programa de pós-graduação \\ faculdade de educação \\ ano 7 - número 15 - 2020}

menos delineadas desdobradas em um tempo serial e cumulativo - a concepção de evolução é central. Todavia, nos últimos anos, o radical neuro alocado a esta palavra parece promover deslocamentos importantes em relação a uma trajetória pré-estabelecida característica da concepção moderna de desenvolvimento. Não pretendemos, no entanto, considerar o neurodesenvolvimento como evolução da concepção de desenvolvimento moderna, mas como noção que comporta linhas de continuidade e diferença. Para além de uma trajetória previamente definida, sua articulação a discussões da biologia como de epigenética e plasticidade cerebral remete a um processo errático e de constante transformação, se diferenciando de uma trajetória evolutiva com etapas delineadas de antemão. Ademais, esse caminho de constante mudança se inicia na infância, mas se estende para o adulto: um corte entre estes dois polos não pode ser entrevisto de forma precisa.

De maneira geral, a ascensão do capítulo Transtornos do neurodesenvolvimento no DSM-5 (APA, 2013) comporta uma lógica que traz consequências importantes para a psiquiatria contemporânea. Nesse capítulo está grande parte das afecções antes pertencentes ao grupo destinado à infância ou consideradas como amiúde iniciadas na infância. Segundo Lima (2020a), com esta seção, configura-se uma espécie de "desaparecimento da infância" no DSM-5, que se completa com a dispersão de outros diagnósticos infantis alocados na mesma categoria dos transtornos adultos. Diante desse quadro, observa-se na psiquiatria um deslocamento das patologias ligadas ao atraso de desenvolvimento transitório localizado na infância para uma perspectiva neurodesenvolvimentista que atravessa o ciclo de vida.

É preciso destacar que a ascensão desse capítulo comporta certa linha de continuidade com a mudança de paradigma consolidada na publicação do DSM-III em 1980, na medida em que se pretendia basear em uma abordagem ateórica e descritiva que tinha como horizonte o projeto de vincular as patologias mentais ao substrato biológico. Este deslocamento é impulsionador do que Shorter (1997) chamou de "segunda psiquiatria biológica", alavancando a intenção de associar os transtornos mentais a problemas neuronais. Seguindo as indicações de Paris 


\section{movim nto \\ revista de educação do \\ programa de pós-graduação \\ faculdade de educação \\ ano 7 - número 15 - 2020}

(2013), as questões que impulsionaram as mudanças em 1980 permanecem presentes no contexto da publicação do DSM-5 (2013), posto que uma psiquiatria biológica não foi consolidada na terceira e na quarta edições do manual.

Neste contexto, o capítulo Transtornos do Neurodesenvolvimento, dentre outros aspectos, consiste na tentativa de dar um destino a estes problemas e, por conseguinte, concentra o projeto da psiquiatria como um todo - principalmente na maneira de se conceber a etiopatogenia dos transtornos mentais. Bishop e Rutter (2008) sustentam que a discussão em torno do neurodesenvolvimento é consequência de um movimento iniciado nos anos 60 e 70 com o diagnóstico "Minimal brain disfunction", que pretendia alocar diferentes sintomatologias em uma única etiopatogênese cerebral, se distanciando de descrições sintomatológicas.

O argumento utilizado para o abandono do capítulo dos diagnósticos usualmente feitos na infância, encontrado no site da APA, parece corroborar esta intenção. A justificativa para a inclusão do radical neuro calca-se principalmente na ideia de que "evidências científicas atualmente colocam vários transtornos, ou mesmo a sua maioria, em um espectro com transtornos intimamente relacionados que apresentam sintomas compartilhados, fatores de risco ambientais, genéticos e possivelmente substratos neuronais compartilhados." (APA, 2013, p.24).

Nesta mesma direção, os editores afirmam que o Transtorno de Déficit de Atenção e Hiperatividade (TDAH)

foi colocado no capítulo sobre os transtornos do neurodesenvolvimento para refletir seus correlatos no desenvolvimento cerebral bem como a decisão no DSM-5 de eliminar o capítulo do DSM-IV que incluía todos os diagnósticos usualmente feitos pela primeira vez na primeira infância, infância ou adolescência. (APA, 2013, p.82)

No próprio manual, todavia, na descrição do TDA/H, mais precisamente no tópico Características Associadas que Apoiam o Diagnóstico, encontramos a seguinte afirmação:

Não há marcador biológico que seja diagnóstico de TDA/H. Como grupo, na comparação com pares, crianças com TDAH apresentam eletrocefalogramas com aumento de ondas lentas, volume encefálico total reduzido na ressonância magnética e, possivelmente, atraso na maturação cortical no sentido póstero-anterior, embora esses achados não sejam diagnósticos. Nos raros casos em que há uma causa 


\section{movim nto \\ revista de educação do \\ programa de pós-graduação \\ faculdade de educação \\ ano 7 - número 15 - 2020}

genética conhecida (p. ex., síndrome do X-frágil, síndrome da deleção 22q11), a apresentação do TDAH ainda deve ser diagnosticada (APA, 2013, p.61).

É interessante assinalar que apesar da intenção explícita, o agrupamento em torno dos transtornos do neurodesenvolvimento, na prática, não se sustenta em marcadores biológicos, que continuam ausentes da clínica psiquiátrica. Ademais, as hipóteses biológicas calcadas na noção de epigenética, que, grosso modo, afirmam a interação entre gene e meio ambiente na origem dos transtornos mentais, bem como a noção de plasticidade cerebral, que apontaria para um caminho errático de constante mudança dos circuitos cerebrais, não são mais bem explicitadas nesse manual diagnóstico.

No entanto, mesmo que não esteja explícito nos manuais, as hipóteses neurodesenvolvimentistas calcam-se, sobretudo, na premissa da interação gene e ambiente gerando marcas biológicas que, por sua vez, poderiam ser delimitadas como causa detectável dos transtornos mentais. O radical neuro alocado ao lado da palavra desenvolvimento aparece como possibilidade (ainda que ainda não consolidada) de aproximar a psiquiatria da neurologia e, com isso, trazer mais legitimidade biomédica à primeira. Este grupo vem, portanto, ganhando um peso importante nas pesquisas atuais, posto que promete um horizonte no qual a psiquiatria, a neurologia e a noção de desenvolvimento se entrelacem de modo inseparável.

Neste âmbito, é possível traçar uma linha de continuidade entre estes objetivos e a diretriz, discutida desde 2008, pelo National Institut of Mental Health (NIMH), em seu plano estratégico. Este estabelece como objetivo primeiro promover descobertas no cérebro e nas ciências comportamentais para impulsionar as pesquisas sobre as causas dos transtornos mentais (NIMH, 2008).

É também nesse contexto que se insere o projeto mencionado anteriormente, intitulado RDoc (Research Domain Criteria), que tem a intenção de classificar transtornos mentais a partir da análise de genes, células, circuitos neurais e de, no limite, prometer mais validade e confiabilidade etiológica do que as classificações existentes. De acordo com Insel e Quirion (2005), o objetivo da década consistia na possibilidade de coincidência entre doença mental e transtorno 


\section{movim nto \\ revista de educação do \\ programa de pós-graduação \\ faculdade de educação \\ ano 7 - número 15 - 2020}

cerebral, sugerindo que "o psiquiatra do futuro terá de ser um cientista do cérebro" (p.5). A chave para se forjar um caminho até os sistemas cerebrais estaria justamente em acompanhar a questão do desenvolvimento - tal como apontam Casey, Oliveri e Insel (2014). Os transtornos do neurodesenvolvimento, portanto, parecem ser o ponto de transição entre o paradigma do DSM-5 e o do RDoC.

Além da articulação da patologia ao desenvolvimento neuronal, os transtornos do neurodesenvolvimento deixam entrever outro movimento importante do quinto manual: a mudança no sistema de classificação das doenças que deixou de ser multi-axial ${ }^{1}$, como o era desde 1980, para tornar-se categorial-dimensional. Sob o viés dimensional, a patologia é vista como um continuum de intensidade, reduzindo a imposição de pontos de corte únicos e definitivos para um limiar patológico - típicos da concepção categorial. O capítulo Transtornos do neurodesenvolvimento ajuda a constituir um olhar longitudinal sobre o curso dos transtornos mentais, característico da perspectiva categorial-dimensional, ao ressaltar um recorte que enfatiza o ciclo vital. Os diagnósticos presentes no capítulo que remete ao neurodesenvolvimento não são exclusivos da infância - diversas patologias nele incluídas antes privilegiadas no âmbito da infância, são estendidas para os adultos, tais como o TDA/H.

Outro aspecto importante consiste no fato de que, de maneira geral, o DSM-5 reflete a tendência de conceber os transtornos mentais articulados a uma diferença quantitativa e contínua entre normal e patológico, sendo a discussão sobre os transtornos do neurodesenvolvimento central neste contexto (PARIS, 2013) ${ }^{2}$. A intenção de circunscrever a patologia como variação quantitativa do desenvolvimento neural normal (entendido como média fisiológica) é claramente explicitada por Casey, Oliveri e Insel (2014) ao assinalar que uma das tarefas mais importantes da nova diretriz de pesquisas no Instituto Nacional de Saúde Mental (NIMH) é delinear o neurodesenvolvimento típico. Referindo-se aos estudos no

\footnotetext{
${ }^{1} \mathrm{O}$ terceiro e o quarto manuais são divididos em cinco eixos. No quinto manual, através de sua perspectiva categorial-dimensional, esta divisão é eliminada.

${ }_{2}^{2}$ Paris (2013) indica que o princípio calcado na ideia de que há uma diferença qualitativa entre normalidade e patologia remete a Kraepelin e se mantém presente nas edições do DSM anteriores ao DSM-III.
} 


\section{movim nto \\ revista de educação do \\ programa de pós-graduação \\ faculdade de educação \\ ano 7 - número 15 - 2020}

campo do Transtorno do Déficit de Atenção e Hiperatividade (TDA/H), os autores afirmam que em relação ao neurodesenvolvimento normal:

(...) a trajetória do neurodesenvolvimento revelou um atraso ao invés de um déficit na maturação cortical, e o atraso mais proeminente - consistente com os problemas característicos do TDAH - foi nas regiões corticais pré-frontais importantes para a construção do controle cognitivo (p.352).

Os editores do manual, por sua vez, apontam que os diagnósticos do grupo do neurodesenvolvimento podem ser feitos tanto em relação ao excesso quanto a déficits e atrasos em atingir os marcos esperados, seja de maneira global, seja em relação a funções específicas, tal como pode ser entrevisto nesse trecho logo no início do capítulo:

Os transtornos tipicamente se manifestam cedo no desenvolvimento, em geral antes de a criança ingressar na escola, sendo caracterizados por déficits no desenvolvimento que acarretam prejuízos no funcionamento pessoal, social, acadêmico ou profissional. Os déficits de desenvolvimento variam desde limitações muito específicas na aprendizagem ou no controle de funções executivas até prejuízos globais em habilidades sociais ou inteligência (APA, 2013, p.31).

Apesar de delinear as características dos atrasos e déficits, o DSM-5 não comporta uma discussão mais detalhada sobre quais os parâmetros de normalidade e patologia balizam os transtornos do neurodesenvolvimento: como melhor delinear as noções de normalidade e patologia a partir de uma definição que supõe a diferença quantitativa entre estes polos? Uma vez que o manual não fornece esses parâmetros, cabe a nós realizar esta tarefa, em interlocução com as ideias do filósofo Georges Canguilhem.

\section{Neurodesenvolvimento, normalidade e patologia}

O debate a respeito dos critérios de normalidade e patologia no campo da saúde tende a opor naturalistas e normativistas. A perspectiva naturalista, que tem como representante Cristopher Boorse, sustenta que os conceitos de saúde e doença são da ordem do fato puramente descritivo, referentes estritamente uma norma biológica (GIROUX, 2011; ALMEIDA FILHO, JUCÁ, 2002). A meta dos naturalistas é mostrar que a distinção entre o normal e o patológico é factual, e o 


\section{movimento \\ revista de educação do \\ programa de pós-graduação \\ faculdade de educação \\ ano 7 - número 15 - 2020}

que se afasta desse padrão passa a ser considerado patológico (GAUDENZI, 2014).

Sob o prisma normativista, as noções de normal e patológico são entendidas como eventos dependentes da experiência subjetiva, de normas e valores morais. Os normativistas se dividem entre os que afirmam que o valor depende do juízo social através do qual se elaboram as normas de saúde e os que acreditam que o valor da saúde é ditado por algo inerente à vida. A normatividade, na primeira perspectiva, é antes de tudo, de natureza social e cultural (GAUDENZI, 2014).

Conforme ressalta Fulford (2001), o que é identificado como doença é dependente da experiência subjetiva do mal-estar que ocorre em um determinado contexto social. O grupo de sintomas adquire um nome e é incluído nas classificações médicas, tornando-se um tipo de patologia. A segunda perspectiva, por sua vez, diz respeito ao normativismo vital defendido por Canguilhem (1966/1995), precursor deste paradigma.

É relevante notar que já na primeira parte do livro O normal e o Patológico, Canguilhem (2000) identifica um dos equívocos do modo clássico de se entender o patológico ao perguntar: "Seria o estado patológico apenas uma variação quantitativa do estado normal?" (CANGUILHEM, 2000, p.19). A discussão empreendida pelo filósofo culmina na sustentação da tese de que considerar o anormal como simples redução ou acréscimo feito sobre determinada norma fisiológica equivale a converter a continuidade entre normalidade e patologia em homogeneidade -postura que acaba por tornar sem sentido a noção de doença, reduzida a uma simples variação (para mais ou para menos) do funcionamento corporal.

Canguilhem (2000) assinala, portanto, a impossibilidade de definir o patológico como variação quantitativa e de reduzir o normal à média estatística, posto que para o autor é apenas no registro dos valores que se pode compreender o fenômeno da doença. Na esteira dessas ideias, seria possível afirmar que onde os médicos dizem que há uma variação quantitativa/objetiva, se esconde uma alteração qualitativa/valorativa. Este aspecto velado apresenta-se muitas vezes, 


\section{movim nto \\ revista de educação do \\ programa de pós-graduação \\ faculdade de educação \\ ano 7 - número 15 - 2020}

segundo Canguilhem (2000), no aparecimento de termos qualitativos (distúrbio, desproporção, desarmonia) inseridos em discursos aparentemente quantitativos (hiper, hipo), sem que os próprios médicos se deem conta.

Esta ambiguidade pode ser notada nas descrições das próprias categorias alocadas sob o guarda-chuva dos transtornos do neurodesenvolvimento, bem como apontado em relação ao manual como um todo: palavras como desvios e transtornos se articulam a expressões como déficits e excessos. Acompanhando o uso destas expressões, é interessante notar, a partir das indicações dos editores sobre os transtornos do neurodesenvolvimento, os padrões diante dos quais os déficits são considerados, tais como nesse trecho:

Os déficits resultam em prejuízos no funcionamento adaptativo, de modo que o indivíduo não consegue atingir padrões de independência pessoal e responsabilidade social em um ou mais aspectos da vida diária, incluindo comunicação, participação social, funcionamento acadêmico ou profissional e independência pessoal em casa ou na comunidade (APA, 2013, p.31. Grifo nosso).

Os valores usados como balizas para o que se considera normalidade calcam-se, portanto, em noções tais como independência pessoal e responsabilidade social - o que, por sua vez, torna patológico tudo que os limita ou exclui. Seguindo mais uma vez as indicações de Canguilhem (2000), ignora-se que "a doença não é apenas o desaparecimento de uma ordem vital fisiológica, mas o aparecimento de uma nova ordem vital" (p.156) - que pode ser entendida como diferença -, mas que espaço a lógica neurodesenvolvimentista abarca para a diferença?

\section{Neurodesenvolvimento e neurodiversidade}

A perspectiva trazida pelos transtornos do neurodesenvolvimento, conforme discutido até então, implica um contexto no qual as patologias mentais são tratadas como produto de variações quantitativas (sejam elas excessos ou déficits) do desenvolvimento neurológico normal - sendo valores como independência e responsabilidade destacados como pano de fundo da discussão. Ademais, conforme explicitado anteriormente, a lógica neurodesenvolvimentista, articulada ao capítulo Transtornos do neurodesenvolvimento, parece estar na esteira de um 


\section{movim nto \\ revista de educação do \\ programa de pós-graduação \\ faculdade de educação \\ ano 7 - número 15 - 2020}

contexto mais amplo ao situar a patologia mental ao nível do desenvolvimento neural. Este paradigma remete ao chamado programa forte das neurociências, que tem como objetivo a aproximação, ou mesmo coincidência, da psiquiatria e da neurologia e se insere em um movimento mais amplo no qual o cérebro ocupa lugar privilegiado em termos de descrição da subjetividade, que foi designado como neurocultura (ORTEGA, 2009).

Alguns fatores, como o progresso das neurociências, o uso de neuroimagens pela mídia, dentre outros, ajudam a circunscrever esse cenário que coloca o cérebro como detentor das propriedades e autor das ações que definem o sujeito. O termo "sujeito cerebral" (EHRENBERG, 2009; VIDAL, 2005; VIDAL, ORTEGA, 2017) aponta para a crença de que o cérebro é a parte do corpo que engloba toda a identidade pessoal.

Esta discussão é, por sua vez, remetida ao que se designou como bioidentidades, isto é, um modo de construção de identidades baseado em parâmetros calcados na corporeidade biológica, contexto no qual a aproximação entre self e corpo se torna quase absoluta (COSTA, 2004). Ao privilegiar a articulação dos transtornos mentais a substratos biológicos, tal como nos transtornos do neurodesenvolvimento, a psiquiatria e suas categorias diagnósticas têm sido um campo importante de formação das bioidentidades. Conforme aponta Lima (2005), mais especificamente no contexto do Transtorno do Déficit de Atenção e Hiperatividade (TDA/H), observa-se o deslocamento sutil da experiência de portar o transtorno para ser um TDA/H.

É nesse contexto que podemos entender a noção de neurodiversidade - no qual paradoxalmente a identidade, a singularidade e a diferença são calcadas em parâmetros ligados ao funcionamento cerebral. O termo neurodiversidade foi cunhado pela socióloga australiana e portadora da síndrome de Asperger Judy Singer, em 1999 e tem como intuito ressaltar que um funcionamento neural divergente consiste em uma diferença e não em doença. Assim como outras diferenças (tais como as de gênero, raça, credo), desta perspectiva, as bioidentidades também comportam singularidades que devem ser respeitadas e 


\section{movim nto \\ revista de educação do \\ programa de pós-graduação \\ faculdade de educação \\ ano 7 - número 15 - 2020}

não essencialmente patologizadas. O movimento da neurodiversidade acolhe 0 paradigma dos estudos sobre deficiência (disability studies) ${ }^{3}$, segundo o qual deficiência e doença não são fatos biológicos, mas construções socioculturais que visam regulamentar os corpos e os cérebros (DAVIS, 1995; DINIZ, 2007; ORTEGA, 2009).

Um campo importante nessas discussões é constituído por pessoas diagnosticadas pelo espectro autista, e mais especificamente os chamados autistas de alto funcionamento - frequentemente diagnosticados com a síndrome de Asperger. O próprio termo transtorno (disorder) vem sendo substituído por condições (do espectro autista), não apenas nos textos dos ativistas da neurodiversidade e suas associações, mas também na própria literatura no campo do cognitivismo.

Para Happé (1999), por exemplo, as características dos autistas equivaleriam mais a um estilo do que a um déficit cognitivo. Já Baron-Cohen (2000) sustentou que o termo diferença era mais adequado à síndrome de Asperger, por ser mais "neutro", "justo" e "desprovido de valor" do que lesão (impairment) e deficiência (disability), os quais se aplicariam apenas a autistas de baixo funcionamento (LIMA, 2020).

Diante desse quadro, se os valores que sustentam a normalidade implícitos na concepção supostamente quantitativa da patologia ancoram-se sob os preceitos da responsabilidade e da independência, as diretrizes dos transtornos do neurodesenvolvimento parecem considerar patológico tudo aquilo que escapa a esta lógica - indo na contramão da discussão sobre a neurodiversidade. A variação pretensamente quantitativa acaba por se articular à diferença qualitativa entendida como patologia e não diversidade, configurando o transtorno a partir de aspectos com valor negativo, como dependência e irresponsabilidade.

\footnotetext{
${ }^{3}$ Este campo propõe a divisão entre " lesão" (impairment) e "deficiência" (disability). Enquanto a primeira remete a uma condição física, a deficiência faz referência a um rótulo imposto socialmente sobre o indivíduo com alguma lesão - uma lesão se torna uma deficiência a partir de um valor compartilhado socialmente (ORTEGA, 2009).
} 


\section{movim nto \\ revista de educação do \\ programa de pós-graduação \\ faculdade de educação \\ ano 7 - número 15 - 2020}

Cabe também ressaltar que este projeto não é estritamente teórico - afinal, estamos no campo da medicina e, mais especificamente, da psiquiatria. Conforme aponta Bezerra (2014), a psiquiatria, mais do que qualquer outra especialidade médica, é inevitavelmente atravessada por duas variáveis que se colocam em constante tensão, trata-se dos polos: conhecimento e cuidado.

No contexto dos transtornos do neurodesenvolvimento, articula-se um novo campo de estudo, de práticas e intervenções médicas no sentido do conhecimento sobre a vulnerabilidade para determinadas doenças. Com a etiologia da doença calcada na ideia de um início precoce relacionado à interação gene-ambiente, notam-se esforços no intuito de antecipar e prever desfechos patológicos, como o screening genético, apoiados na expectativa de que seja possível identificar com antecedência os indivíduos propensos a adoecer na idade adulta. Quais seriam as consequências desta perspectiva teórico-clínica para a infância e mais especificamente na interseção com o campo da educação?

\section{O governo da Infância e a educação na contemporaneidade:}

\section{empreendedorismo, risco e neurodesenvolvimento}

A infância, tomada como período de início, porém não exclusivo, dos transtornos do neurodesenvolvimento, torna-se um caso particularmente ilustrativo neste contexto. Isto porque, articulada à noção de desenvolvimento moderna, a infância vinculava-se principalmente à ideia de dependência e cuidado. A infância moderna, segundo Wells (2011) foi produzida por novas racionalidades e técnicas de governamentalidade ${ }^{4}$, que instauraram normas para gerir a vida da criança, normas principalmente de cunho disciplinar.

Nas sociedades disciplinares, o poder tem como função o adestramento feito através da criação de instituições, como a escola, e do uso de instrumentos, como

\footnotetext{
${ }^{4}$ No caminho teórico de Foucault, a noção de governabilidade remete principalmente ao uso do poder e ao conjunto de normas comportadas por cada tipo de poder, compondo práticas coercitivas específicas. Destacamse, assim, diferentes modos de governabilidade ligados principalmente ao poder soberano, disciplinar e ao biopoder, engendrando o desenvolvimento de técnicas coercitivas e saberes distintos.
} 


\section{movim nto \\ revista de educação do \\ programa de pós-graduação \\ faculdade de educação \\ ano 7 - número 15 - 2020}

o exame. A criança que deve ser cultivada para se tornar um adulto tem como correlato o nascimento da escola como meio de educação.

Wells (2011) assinala que a emergência de certa maneira de se conceber a infância, marca da modernidade, coincide com uma forma de se exercer o poder disciplinar e avança na direção de um biopoder ou uma política da vida - a biopolítica (FOUCAULT, 2001). Quando a própria vida se torna alvo de tecnologias de poder, as crianças, sua gestação, seu nascimento, bem como o contorno de seu desenvolvimento, que ganha aos poucos um caráter normativo, destacam-se como objetos de governamentalidade.

Conforme apontam Ferreira e Araújo (2009), em relação ao tema da escolarização, esta forma de governabilidade implanta-se no domínio escolar sob o pretexto de igualdade e cidadania. A educação passa, assim, a ser considerada condição para o progresso social e uma espécie de obrigação do Estado, uma vez que permitiria o desenvolvimento da população na direção de adultos civilizados e educados. A escola pública, obrigatória e para todos, além de um projeto de nação (PATTO, 2000), é engendrada pelo esforço destas novas técnicas de gestão naturalizantes, provocando o nascimento do interesse nas investigações psicológicas que culminará em uma série de saberes sobre a infância, como a psicologia do desenvolvimento.

Concomitantemente ao estabelecimento de instituições com o intuito de regular o comportamento infantil, há a configuração de uma série de especialistas que versam sobre a maneira de educar crianças, bem como a formalização de regimes de disciplina que devem caracterizar o desenvolvimento normal (NADESAN, 2010). O governo da vida na infância, neste contexto, visa circunscrever aquilo que pode retardar ou interromper o desenvolvimento natural, no campo de saberes médicos ou jurídicos, por exemplo. Este processo atinge seu ápice a partir primeira metade do século $X X$, quando a especificidade da infância é estudada pela psiquiatria, psicanálise, psicologia, e pedagogia, dentre outros (FERREIRA, 2013). 


\section{movim nto \\ revista de educação do \\ programa de pós-graduação \\ faculdade de educação \\ ano 7 - número 15 - 2020}

A partir do estabelecimento de profissionais detentores de saber sobre as crianças, surge um crescente alarde em torno da vulnerabilidade deste período de vida. Diante deste quadro, configura-se o cenário que Nadesan (2010) denomina de "infância em risco". As crianças, especialmente aquelas das classes mais altas da sociedade, passaram a ser vistas, principalmente a partir da metade do século $\mathrm{XX}$, como em risco no campo educacional, cultural e ambiental, requerendo cuidado parental e de instituições apropriadas desde a primeira infância.

Conforme apontam Nadesan (2010) e Wells (2011), este cenário foi se reconfigurando significativamente ao longo da segunda metade do século XX e principalmente no século XXI, o que coincide com o deslocamento do papel social da infância. Nadesan (2010), ao tratar da infância sob a ótica do risco e as formas de governamentalidade direcionadas a esta, assinala uma reformulação destas práticas no século XXI, principalmente na passagem da política de bem-estar social para a lógica neoliberal. Destaca-se, no campo da saúde, o deslocamento da ênfase de riscos em relação a agentes patogênicos externos para riscos genéticos, questão central para a noção de neurodesenvolvimento.

Segundo a autora, a economia de mercado é de extrema importância para a maneira de elaborar as políticas públicas em relação à infância. Em sintonia com o que se convencionou chamar de sociedade de risco (BECK,1992), na qual o sentimento de insegurança e a necessidade de autogoverno impulsionam o exercício da auto-reflexividade incessante na busca da performance adequada, Nadesan (2010) prevê que as concepções da infância em torno de características como dependência e vulnerabilidade serão cada vez mais desafiadas pelo novo ambiente econômico que, por sua vez, demanda soluções de problemas na direção do gerenciamento de riscos de maneira individualizada.

De acordo com Castro (2013), o capitalismo tardio instala uma diferença importante da posição social que a infância vinha ocupando na sociedade moderna, desencadeando um processo através do qual o papel do jovem e da criança na cultura está em constante redefinição. Na qualidade de consumidora, a criança foi alçada ao mesmo status do adulto. Desmonta-se, assim, a visão de que as crianças 


\section{movim nto \\ revista de educação do \\ programa de pós-graduação \\ faculdade de educação \\ ano 7 - número 15 - 2020}

deveriam esperar por um tempo ulterior para se integrarem na dinâmica social (CASTRO, 2013). A infância passa assim a responder às necessidades mercadológicas como personagem midiático do novo imaginário capitalista.

No campo das indústrias farmacêuticas, também é possível observar esta lógica. Segundo Angell (2007), os esforços desse segmento se localizam principalmente na direção de angariar novos mercados consumidores, sendo a infância um importante alvo neste processo. Além disso, pode-se dizer que a infância tem papel importante, senão decisivo, na lógica de prorrogação da patente de medicamentos.

Nos EUA, por exemplo, caso um medicamento tenha seu uso aprovado pela FDA para a infância, sua patente pode ser estendida em até seis meses (ANGELL, 2007). Este fato impulsiona pesquisas de medicamentos para crianças e desloca os olhares para esta faixa etária, especialmente no crescente mercado de psicofármacos, que estão entre os medicamentos mais consumidos pelas crianças e adolescentes norte-americanos - com destaque para os remédios para TDAH (HALES et al., 2018).

Esta perspectiva se associa a uma mudança mais ampla no regime de poder: a passagem da sociedade disciplinar para a sociedade de controle, desenvolvida por autores como Deleuze (1992). Conforme explicitado anteriormente, enquanto a sociedade disciplinar se caracteriza pelo confinamento à interioridade dos espaços, nas sociedades de controle a vigilância se expande para os espaços abertos. $O$ fim dos contornos bem definidos, assim como os muros das instituições, indica também o apagamento dos limites entre dentro e fora, público e privado.

$\mathrm{Na}$ sociedade de controle, o poder passa a operar através dos dispositivos informacionais, possibilitando modulações intermitentes dos corpos. A formação, por exemplo, torna-se contínua e permanente: não se trata mais de seguir moldes, mas de modular-se continuamente. De acordo com Chevitarese e Pedro (2005), enquanto a norma moderna estabelecia uma lógica dual (na escola, por exemplo, “aprovação/ reprovação"), o contemporâneo apresenta-se como um horizonte infinito e incomensurável de maximização de desempenhos e competências. As 


\section{movim nto \\ revista de educação do \\ programa de pós-graduação \\ faculdade de educação \\ ano 7 - número 15 - 2020}

palavras de ordem dos dias de hoje giram em torno da flexibilidade e constante mudança.

Neste contexto, nota-se o deslocamento da perspectiva desenvolvimentista nas discussões em torno da educação infantil. Isto porque a criança deixa de ser entrevista sob o viés evolutivo de um desenvolvimento natural previsível para dar lugar à perspectiva que comporta certa performatividade e uma trajetória irregular. Nesta mesma direção, observa-se principalmente discussões em torno do que se convencionou chamar de "pedagogia das competências" (RAMOS, 2001) em contraposição ao projeto pedagógico divido por fases correspondentes às faixas etárias. Segundo Le Boterf (2003), competência significa a possibilidade de ação ajustada diante de situações complexas, imprevisíveis, mutáveis e sempre singulares.

Uma pedagogia baseada em competências considera a criança um sujeito autônomo e competente em relação ao uso do saber, deixando de circunscrevê-la como um ser que deve passar por etapas pré-formadas de desenvolvimento. Seguindo as indicações de Ramos (2001), consolida-se, através deste ideário, a tendência da profissionalização de tipo liberal, baseada no princípio da adaptabilidade individual às mudanças socioeconômicas. Isto é, a criança pode se tornar um sujeito autônomo da sua aprendizagem e, concomitantemente, um sujeito que desde o princípio deve recorrer as suas habilidades para se adaptar às adversidades do contexto. Neste cenário, os objetivos pedagógicos passam a visar as competências que podem ser adquiridas pelos alunos ao longo do seu percurso acadêmico. O professor, ou o adulto, neste processo, deixa de ser um modelo a ser alcançado para se tornar uma espécie de fiador de saberes, organizador de aprendizagens e, mais especificamente, gestor e regulador de percursos formativos que são singularizados de acordo com cada situação problema.

A infância, neste contexto, deixou de ser entendida como preparação para a fase adulta, consolidando uma concepção calcada nas ideias de competência e agência. A ideia de competência, segundo Castro (2013), está inserida em uma noção de sujeito individualizado, entendido como independente dos demais, guiado 


\section{movim nto \\ revista de educação do \\ programa de pós-graduação \\ faculdade de educação \\ ano 7 - número 15 - 2020}

pela razão e capaz de decidir e escolher sozinho - o projeto do que se concebe como um cidadão torna-se marcado cada vez menos pelo signo dos direitos, abrindo espaço para a concepção de empreendedor, isto é, aquele que empreende seus próprios agenciamentos.

No mundo contemporâneo, os valores que regem o imaginário social exigem que o indivíduo seja um empreendedor de sua própria vida: deve-se começar desde cedo a façanha de se tornar algo. As etapas de desenvolvimento rumo ao adulto são senão extintas, ao menos camufladas e o neurodesenvolvimento é emblemático deste deslocamento. A criança contemporânea, conforme ressalta Nadesan (2010), é cercada com a responsabilidade de assumir habilidades e conhecimentos necessários para alcançar sucesso econômico e social - o que caracteriza notadamente a lógica das competências na educação -; o desenvolvimento cerebral, por sua vez, aparece como ator principal neste processo.

Neste contexto, é interessante destacar, partindo do estudo feito por Lisboa (2016), a consolidação do discurso que tem sua origem remetida ao século XIX, calcado na relação entre cérebro e educação, denominado de neuroeducação.

A neuroeducação, bem caracterizada pelo movimento que se intitula Mind, Brain and Education, pretende articular teoria e prática integrando três grandes disciplinas: neurociência, psicologia e pedagogia. O objetivo, grosso modo, consiste em estudar como os seres humanos aprendem, de forma a desenvolver métodos de ensino mais efetivos que potencializem as competências de cada estudante (LISBOA, 2016).

Com a pretensão de representar uma mudança de paradigma das práticas de ensino, posto que implica uma fundamentação baseada em evidências, a proposta consiste, principalmente, em educar a partir do cérebro ou, mais especificamente, educar o cérebro. O cérebro tem, portanto, ainda segundo Lisboa (2016), ocupado o lugar de protagonista do processo educacional: é para este órgão (que comporta inúmeros sentidos) que o ensino e a aprendizagem são 


\section{movim nto \\ revista de educação do \\ programa de pós-graduação \\ faculdade de educação \\ ano 7 - número 15 - 2020}

pensados - neste contexto, o cérebro é o sujeito que aprende e se molda de acordo com as competências adquiridas.

No entanto, conforme aponta Lisboa (2016), o que se entende por cérebro está longe de ser unívoco. Para o autor, não se trata de um cérebro analisado sob diversos vieses, mas, efetivamente, de múltiplos cérebros, isto é, múltiplas versões do cérebro performadas por diferentes atores. Lisboa (2016) afirma que a característica de mutabilidade - ou "neuroplasticidade" - deste cérebro comporta ao menos três sentidos. O primeiro deles diz respeito à afirmação de que o cérebro se desenvolve, modificando-se ao longo do tempo. Um segundo aspecto consiste na ideia de que o cérebro altera as suas configurações e suas conexões em resposta às influências ambientais e sociais. Já o terceiro sentido implica a consideração do cérebro como órgão que é capaz de alterar suas funções e até mesmo a sua estrutura diante de uma lesão.

A neuroplasticidade, para além de conceito técnico-científico, serve como metáfora da suposta capacidade ilimitada do ser humano mudar, aprender, se reconfigurar e se maximizar - capacidade esta que se manifesta notadamente na noção contemporânea de infância. A convergência entre o novo paradigma da neurociência psiquiátrica e a infância contemporânea tem impactos na identidade infanto-juvenil e penetra no ambiente escolar de modo marcado e distinto de tudo que já tínhamos visto antes.

Na medida em que a escola, já afetada pela ideologia do empreendedorismo, passa a incorporar o vocabulário da neurociência, seja por meio da neuroeducação - para maximizar o desempenho cerebral dos normais - seja por meio de categorias como as incluídas sob os transtornos do neurodesenvolvimento - para perscrutar os desviantes -, o impacto na identidade da criança ou adolescente é inevitável.

Por um mecanismo de looping (HACKING, 1995), os tipos humanos classificados como TDAH, TEA ou Asperger, TOD etc., passam a interagir com a classificação e enxergar, descrever e experimentar a si mesmos por meio das lentes do diagnóstico. Junto com isso, a localização do problema no cérebro tem 


\section{movim nto \\ revista de educação do \\ programa de pós-graduação \\ faculdade de educação \\ ano 7 - número 15 - 2020}

impactos adicionais em sua autopercepção. No caso de crianças e adolescentes, essa autopercepção é mediada por instituições como a escola (e a família), por isso é fundamental que o campo da educação dialogue de modo crítico com os saberes que vêm da psiquiatria, da psicologia e da neurociência, campos nos quais o neurodesenvolvimento tem sido figura de destaque.

\section{Considerações finais}

A infância, seguindo as indicações de Rose (1999), é o setor da existência mais intensamente governado - de diferentes maneiras ao longo do tempo e por variados atores, discursos e saberes. No entanto, aquilo que se entende por infância, como é sabido, não é um dado, mas suas fronteiras e características variam no tempo, bem como os diferentes campos de saber que versam sobre ela. Nesse sentido, nossa hipótese é a de que a perspectiva do neurodesenvolvimento é produto e produtora de determinada forma de se conceber a infância, bem como de algumas práticas de controle (ou talvez governabilidade) ligadas a este período. De uma concepção do desenvolvimento ligada a fases pré-estabelecidas para a perspectiva que comporta uma espécie de continuum performativo com a idade adulta, a infância e o (neuro)desenvolvimento caminham lado a lado.

Ainda que seja impossível negar os avanços no conhecimento sobre a estrutura e o funcionamento cerebral nos últimos anos, a promessa neurodesenvolvimentista não se consumou. Inúmeros obstáculos são descritos no sentido de circunscrever com mais precisão uma etiologia biológica para os transtornos mentais. Diante das dificuldades expostas na consolidação deste paradigma, as noções de risco e vulnerabilidade ganham destaque. O risco é tomado de forma individual e cada indivíduo terá o destino que merece: dependendo de suas heranças genéticas, de seu cérebro e suas escolhas. O risco na infância é apenas o começo de uma trajetória que se estenderá por toda a vida de cada indivíduo, ou melhor, por todo seu neurodesenvolvimento. Em consequência, tratar, ou melhor, prever é uma tarefa pessoal de autocuidado: cada um tomando conta do seu neurodesenvolvimento. 


\section{movim nto \\ revista de educação do \\ programa de pós-graduação \\ faculdade de educação \\ ano 7 - número 15 - 2020}

As noções de competência, agência e resiliência, em sintonia com a concepção de neurodesenvolvimento, produz uma compreensão do normal e do patológico que se aproxima perigosamente de prescrições de cunho moral. Como identificar fatores que podem levar a criança a desenvolver um transtorno mental? Como a escola pode atuar na busca por 'suspeitos', visando contribuir na prevenção ou intervenção precoce? Estas são perguntas que a psiquiatria articulada ao neurodesenvolvimento tenta responder sob argumentos aparentemente científicos, prescrevendo um espaço escolar que monitore os riscos e estimule o empreendedorismo, a flexibilidade e a adaptabilidade - quem sabe assim, o neurodesenvolvimento normal poderá ser assegurado, e os desvios patológicos, evitados.

A escola precisa estar atenta a esses movimentos que misturam ciência, ideologia e moral neoliberal em proporções difíceis de se distinguir a priori. Isso poderia, à primeira vista, parecer estranho ao campo pedagógico, mas, como tentamos demonstrar, tem reflexos diretos nele. A noção de neurodesenvolvimento pode ser relevante na busca pela compreensão multifacetada das peculiaridades, desafios e obstáculos da vida infantil e da realidade escolar, desde que a escola se insira como agente desse processo, ao invés de receptora passiva do saber neuropsiquiátrico.

\section{Referências}

ALMEIDA FILHO, Naomar; JUCÁ, Vládia. Saúde como ausência de doença: crítica à teoria funcionalista de Christopher Boorse. Ciência \& Saúde Coletiva, vol 7, pp. 879-889, 2002.

AMERICAN PSYCHIATRIC ASSOCIATION. Diagnostic and Statistical Manual of Mental Disorder DSM-III. Draft, 1980.

AMERICAN PSYCHIATRIC ASSOCIATION. Diagnostic and Statistical Manual of Mental Disorder DSM-5. Draft, 2013.

ANGELL, M. A verdade sobre os laboratórios farmacêuticos. Rio de Janeiro/São Paulo: Editora Record, 2007. 


\section{movimento \\ revista de educação do \\ programa de pós-graduação \\ faculdade de educação \\ ano 7 - número 15 - 2020}

BARON-COHEN, Simon. Is Asperger syndrome/high functioning autism necessarily a disability? Development and Psychopathology, vol. 12, pp. 489-500, 2000

BECK, Ulrich. Risk Society: Towards a New Modernity, Londres: Sage, 1992.

BEZERRA Jr., Benilton. A psiquiatria contemporânea e seus desafios. In: ZORZANELLI, Rafaela; BEZERRA Jr., Benilton; COSTA, Jurandir Freire. (orgs.) A criação de diagnósticos na psiquiatria contemporânea. Rio de Janeiro: Gramond, p.9-34. 2014.

BISHOP, Dorothy.; RUTTER, Michael. Neurodevelopmental disorders: conceptual issues. In: RUTTER Michael et a (ed.). Rutter's child and adolescent psychiatry. Oxford: Blackwell. p. 32-41, 2008

CANGUILHEM, Georges. O Normal e o Patológico, Rio de Janeiro, Forense Universitária, $5^{\mathrm{a}}$ edição, 2000 (originalmente publicado em 1966).

CASEY, B.J.; OLIVERI, Mary Ellen; INSEL, Thomas. A neurodevelopmental perspective on the research domain criteria (RDoC) framework. Biol Psychiatry, $v$. 5, n. 76, pp.350-353, jan. 2014

CASTRO, Lucia. O futuro da infância e outros escritos. Rio de Janeiro: Sete letras, 2013.

CHEVITARESE, Leandro; PEDRO, Rosa Maria Leite Ribeiro. Da sociedade disciplinar a sociedade de controle: a questão da liberdade por uma alegoria de Franz Kafka, em O Processo, e de Phillip Dick, em Minority Report. Estudos de Sociologia, v.8, n. 12, pp. 129-162, 2005.

COSTA, Jurandir Freire. As fronteiras disputadas entre normalidade, diferença, patologia In: ZORZANELLI, R.; BEZERRA J.R.B.; COSTA, J. (Org) A criação de diagnósticos na psiquiatria contemporânea. Rio de Janeiro: Gramond, 2014. p.171-190

DAVIS, Lennard J. Enforcing normalcy. Disability, deafness and the body. London, New York: Verso, 1995.

DINIZ, Debora. O que é deficiência. São Paulo: Brasiliense, 2007.

EHRENBERG, Alain. Le sujet cérébral. Revue Esprit, n.309, pp.130-155, 2004.

EHRENBERG, Alain. O sujeito cerebral. Psicologia Clínica. Rio de Janeiro, v. 21, n. 1, p. 187-213, 2009. 


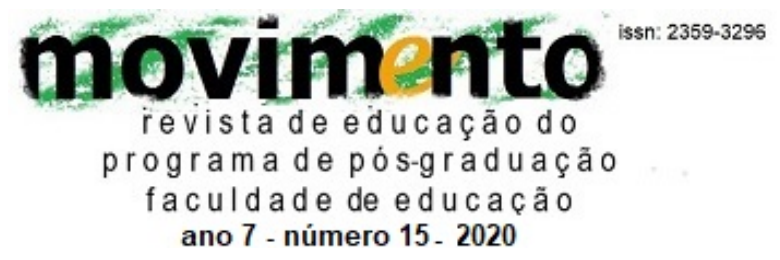

EHRENBERG, Alain. $\mathbf{O}$ culto da performance. Da aventura empreendedora à depressão nervosa. Aparecida: Ideias \& Letras, 2010.

EME, Robert. Developmental psychopathology: A primer for clinical pediatrics. World journal of psychiatry, v.7, n.3, p. 159-162, 2017.

FERREIRA, Arthur; ARAUJO, S. F. Da invenção da infância à psicologia do desenvolvimento. Psicologia em Pesquisa, v. 3, n. 2, p. 3-12, 2009.

FERREIRA, Arthur. Infância, desenvolvimento e escola: a ordem dofatores altera o produto subjetivo. In: LEONARDO A. (Org) A psicologia contra a natureza, reflexões sobre os múltiplos da atualidade. Niteroi: Editora da UFF, 2013.

FOUCAULT, Michel. Aula de 19 de março de 1975. In: Os anormais: curso no Collège de France (1974-1975). São Paulo: Martins Fontes, 2001.

FULFORD, Bill. What is (mental) disease? An open letter to Christopher Boorse. Journal of Medical Ethics, vol. 27, pp. 80-85, 2001.

GAUDENZI, Paula. A tensão naturalismo/normativismo no campo da deinição da doença. Revista Latinoamericana de Psicopatologia Fundamental, São Paulo, v. 17, n. 20, pp.911-924, dez. 2014.

GIROUX, Élodie. Canguilhem, Boorse y Nordenfelt: entre naturalismos y normativismos. In: Ion Arrieta Valero (org) Después de Canguilhem: definir la salud y la enfermedad. Bogota: Universidad El Bosque, 2011.

HAPPÉ, F. Autism: cognitive deficit or cognitive style? Trends in Cognitive Sciences, v. 6, n. 3, p. 216-222, 1999.

HALES, Craig; KIT, Brian; GU, Qiuping; OGDEN et. al. Trends in Prescription Medication Use Among Children and Adolescents. JAMA, United States, v. 19, n. 319, 2018.

INSEL, Thomas; QUIRION, Remi. Psychiatry as a Clinical Neuroscience Discipline. JAMA, n. 294, v.1, p. 2221-2224, 2005.

INSEL, Thomas. (Director's Blog). NIMH. Transforming Diagnosis. 29 abr 2013. Disponível em:

http://www.nimh.nih.gov/about/director/2013/transforming-diagnosis.shtml

Acesso em 15 mar 2020.

LE BOTERF, Guy. Desenvolvendo a competência dos profissionais. Porto Alegre: Artmed Editora, 2003. 


\section{movim nto \\ revista de educação do \\ programa de pós-graduação \\ faculdade de educação ano 7 - número 15 - 2020}

LIMA, Rossano Cabral. Somos todos desatentos? O TDA/H e a construção de bioidentidades. Rio de Janeiro: Relume Dumará, 2005.

LIMA, Rossano Cabral. Infância e adolescência em tempos de DSM-5 e CID 11: trajetórias da classificação e perspectivas de investigação crítica. In: Catão, Inês (org.). Mal-estar na infância e medicalização do sofrimento: quando a brincadeira fica sem graça. Salvador: Ágalma, 2020a.

LIMA, Rossano Cabral. Normalidade e patologia nas classificações psiquiátricas: dos transtornos mentais infanto juvenis à síndrome da criança normal. No prelo. 2020b.

LISBOA, Felipe. $O$ cérebro vai à escola. Aproximações entre neurociências e educação no Brasil. Jundiaí: Paco Editorial, 2016.

NADESAN, Majie Holmer. Governing Childhood into the 21st Century: Biopolitical Technologies of Childhood. Management and Education. Critical Cultural Studies of Childhood Series. New York: Palgrave Macmillan, 2010.

NESTLER, Eric. Epigenetic mechanisms in psychiatry. Biological Psychiatry, v. 65, n. 3, p. 189-190, 2009.

ORTEGA, Francisco. Deficiência, autismo e neurodiversidade. Ciênc. saúde coletiva; vol. 1, n.14, pp.67-77, 2009.

PARIS, James. The Ideology Behind DSM-5. In: PARIS, Joel; PHILLIPS, James. (Eds.). Making the DSM-V concepts and controversies. New York: Springer, p.39-46, 2013.

PATTO, Maria Helena de Souza. A produção do fracasso escolar. Histórias de submissão e rebeldia. São Paulo: Casa do Psicólogo, 2000.

RAMOS, Marise. A pedagogia das competências: autonomia ou adaptação? São Paulo: Cortez, 2001.

SHORTER, Eduard. A History of Psychiatry. From the Era of the Asylum to the Age of Prozac. Jonh Wiley \& Sons, Inc, 1997.

SINGER, Judy. Why can't you be normal for once in your life?' From a 'problem with no name' to the emergence of a new category of difference. In: Corker M, French S, editors. Disability discourse. Buckingham: Open University Press; 1999. p. 5967. 


\section{movim nto \\ revista de educação do \\ programa de pós-graduação \\ faculdade de educação ano 7 - número 15 - 2020}

SILVA-FREITAS, Luna; ORTEGA, Francisco. A epigenética como nova hipótese etiológica no campo psiquiátrico contemporâneo. Physis. v.24, n.3, pp. 54-67, 2014.

VIDAL, Fernando. The Cerebral Subject: a Historical and Conceptual Overview, Psychiatrie, sciences humaines, neurosciences, v. 3, n. 11, pp. 37-48, 2005.

VIDAL, Fernando; ORTEGA, Francisco. Being Brains. Making the Cerebral Subject. New York: Fordham University Press, 2017.

ZORZANELLI, Rafaela; DALGALARRONDO, Paulo; BANZATO, Claudio. O projeto Research Domain Criteria e o abandono da tradição psicopatológica. Revista latinoamericana de Psicopatologia Fundamental, v. 17, n.2., p.328-341, 2014.

WELLS, Karen. The Politics of Life: Governing Childhood. Global Studies of Childhood, v. 1 n. 1, p. 15-25, 2011.

\section{DADOS SOBRE OS AUTORES}

THAIS KLEIN é doutora em Teoria Psicanalítica pela Universidade Federal do Rio de Janeiro (UFRJ), doutora em Saúde Coletiva pela Universidade do Estado do Rio de Janeiro (UERJ), professora do Centro Universitário Augusto Motta (UNISUAM) e do Programa de Pós-graduação em Psicanálise e clínica da contemporaneidade (UNISUAM).

E-mail: thaiskda@gmail.com

ROSSANO CABRAL LIMA é doutor em Saúde Coletiva pela Universidade do Estado do Rio de Janeiro (UERJ), com período intercalar no Instituto Max Planck de História da Ciência (Berlim, Alemanha), vice-diretor e professor-psiquiatra Associado do Instituto de Medicina Social da Universidade do Estado do Rio de Janeiro (UERJ).

E-mail: rossanolima1@gmail.com 